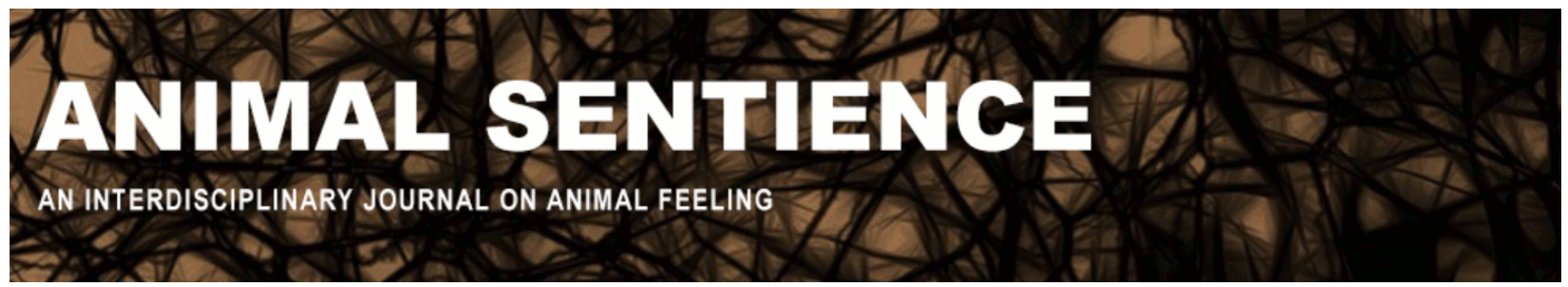

Lainé, Nicolas (2020) Anthropology and conservation. Animal Sentience 28(5)

DOI: $10.51291 / 2377-7478.1560$

Date of submission: 2020-02-25

Date of acceptance: 2020-02-27

(c) (i)

This article has appeared in the journal Animal

Sentience, a peer-reviewed journal on animal

cognition and feeling. It has been made open access,

free for all, by WellBeing International and deposited

in the WBI Studies Repository. For more information,

please contact

wbisr-info@wellbeingintl.org.

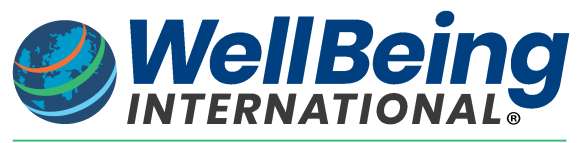

SOLUTIONS FOR PEOPLE, ANIMALS AND ENVIRONMENT 


\title{
Anthropology and conservation
}

\author{
Commentary on Baker \& Winkler on Elephant Rewilding
}

\author{
Nicolas Lainé \\ French National Research Institute for Development (IRD), Paris
}

\begin{abstract}
Baker \& Winkler make a welcome contribution to elephant conservation in Thailand in advocating a role for joint human/elephant labor and local expertise in rewilding. Their argument would benefit, however, if it drew more upon the local ethnographic evidence. Ethnocentric notions such as "welfare" and "wellbeing" may not fit into the local perception of pachyderms.
\end{abstract}

Nicolas Lainé holds a PhD in anthropology from ParisWest University (2014). His research focuses on human-animal relations in Asia, the links between health and biocultural diversity, and the decolonization of science. He also serves as an expert member of the IUCN/SSC Asian elephant Specialist Group. Website

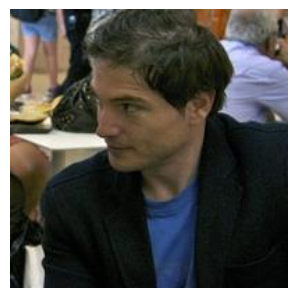

Local knowledge provides cultural nodes for species conservation. For years mainstream projects in Asia have been based on a dualistic approach dominated by an "elephantocentric" vision of conservation (Lainé 2018a). Baker \& Winkler (B\&W) (2020) make a welcome contribution to elephant conservation in proposing to take into account the knowledge and know-how of the Karen Hill Tribe in Thailand. The term "mahout" has many disparate senses today, far from its historical meaning: the art of living and sharing life with elephants. B\&W rightly distinguish mahouts working in tourist camps from those living with elephants in villages. A more detailed ethnographic analysis of the daily relationship between Karen mahouts and elephants would have been more informative. B\&W's target article seems to be midway between a conservation paper on rewilding and a (timid) anthropological paper. The two could have been better articulated and put at each other's service.

The growing ethnographic literature on humans and elephants in Asian villages describes the living conditions of these animals and their unique bonds with mahouts and owners. This is far different from the camps where young inexperienced mahouts are often employed (Crawley et al. 2019). In villages, both species have the same life expectancy; living with an elephant is not the same as living with a cat or a dog, with their much shorter life spans. Elephants, owners and mahouts often spend several decades together. This leaves time for each of the protagonists to get to know one another through shared experiences. Elephants have access to various spaces in the forest and the village. They are generally not chained all day long and are released by night. (Hence Asian elephants do not quite fit into the category of domesticated animals.) This has been documented with the Khamti in Northeast India (Lainé 2018b), the Tai-Lue in Laos (Lainé 2017), and the Shan in Myanmar (Shell 2019). The movement of elephants between villages and forests 
allows them to play a crucial role in ecosystem regeneration as mega-gardeners of ecosystems; this supports B\&W's argument.

Labor as a crucial dimension sustaining the human-elephant socioecological system. B\&W propose not just to rewild elephants in the forest (something that can be discussed) but to integrate their close human partners in this venture. Nowadays, engaging humans and elephants in work seems to be crucial for the survival of the elephant species (Lainé 2019). Since the second half of the twentieth century, most nation-states in Asia have banned logging, rendering thousands of elephants and their owners across the continent jobless. Soon thereafter, through a process of commodification of Nature (Duffy \& Moore 2010), pachyderms were declared a cultural heritage and elephant tourism the means of conserving the species. This has been criticized by many animal activists and conservationists (Bone \& Bone 2015; Kopnina 2016).

The activities in which animals are used do indeed raise many questions like the ones raised by Kopnina (2020) in her commentary because the activities are often perceived only in terms of domination or exploitation. The shared context of work is a space of negotiation between species, however, where interspecies relations are not always a matter of humans dominating animals (Porcher 2017). Putting work at the center of human-elephant relations obviously does not mean that any task performed by an elephant is justifiable. Elephant conservation based on interspecies labor needs to focus on the diversity of both species' attachments to life and forms of living. This is important not only for interspecies relations and for individual sentience and subjectivity; it also allows joint productivity to be considered as a component of the ecosystem as a whole (Lainé 2019).

Thus, even though, as noted by commentator Suter (2020), Asian elephant camps are places where mahout skills can be used for elephant management, there is a need to invent new ways of working with elephants across Asia. B\&W's proposal to rewild elephants with the help of their mahouts is clearly a way to make human/elephant systems more resilient and adaptive socio-ecologically.

When ethnocentrism resists. There is some residual ethnocentric thinking in B\&W's proposal to rewild elephants. An example is the western concept of animal health and needs in terms of "welfare" and "well-being," which B\&W take for granted without discussion. If they actually took Karen knowledge and know-how as a cornerstone of their project, they could ground it in the Karen perception of environment and elephant health. Is there a Karen concept that might correspond to our western notion of "wild" (and ultimately "rewilding"): How do such concepts shape local practices? Anthropological enquiry based on immersive fieldwork conducted in the local language can shed light on other views. If pursued by the authors, this could be a key to the success of their project. 


\section{References}

Baker, L., \& Winkler, R. (2020) Asian elephant rescue, rehabilitation, and rewilding. Animal Sentience 28(1).

Bone, K., \& Bone, J. (2015) The same dart trick: The exploitation of animals and women in Thailand tourism. In K. Markwell (ed.), Animals and tourism: Understanding diverse relationships. Channel View Publications.

Crawley, J.A.H., Lahdenpera, M., Seltmann, M.W., Htut W., Aung, H.H., Nyein, K., \& Lummaa, V. (2019) Investigating changes within the handling system of the largest semi-captive population of Asian elephants. PLoS One 14 (1): e0209701.

Duffy, R., \& Moore, L. (2010) Neoliberalising nature? Elephant-back tourism in Thailand and Botswana. Antipode 42 (3): 742-766.

Kopnina, H. (2016) Wild animals and justice: the case of the dead elephant in the room. Journal of International Wildlife Law \& Policy 19 (3): 219-235.

Kopnina, H. (2020) Of elephants and men. Animal Sentience 28(2).

Lainé, N. (2017) Bo mee xang pa kor bo mee xang (sans éléphants de forêt, il n'y a plus d'éléphants). Revue Peninsule 75 (2): 73-99.

Lainé, N. (2018a) Asian elephants conservation: Too elephantocentric? Towards a biocultural approach of conservation. Asian Bioethics Review 10 (4): 279-293.

Lainé, N. (2018b) Why the Khamti did not domesticate their elephants? Building a hybrid sociality with tamed elephants. In C. Stépanoff \& J.-D. Vigne (eds.), Hybrid Communities. Biosocial Approaches to Domestication and Other Trans-species Relationships. New York: Routledge, pp. 221-235.

Lainé, N. (2019) 5. For a new conservation paradigm: Interspecies labor. Examples from humanelephant working communities. In J. Porcher \& J. Estebanez (eds.), Animal Labor. A New Perspectives on Human-Animal Relations. Bielefeld: Transcript - Verlag, pp. 81-101.

Porcher, J. (2017) The Ethics of Animal Labor: A Collaborative Utopia. Palgrave: Macmillan. Shell, J. (2019) Giants of the Monsoon Forest: Living and Working with Elephants. New York: W.W. Norton.

Suter, I. (2020) Rewilding or reviewing: Conservation and the elephant-based tourism industry. Animal Sentience 28(3). 


\section{Call for Papers}

Special Issue of the Journal of Consciousness Studies

Plant Sentience: Theoretical and Empirical Issues

Guest Editors: Vicente Raja (Rotman Institute of Philosophy, Western University) Miguel Segundo-Ortin (School of Liberal Arts, University of Wollongong)

In this special issue, we address the issue of plant sentience/consciousness from different disciplines that combine both theoretical and empirical perspectives. Some of the questions to be addressed in the special issue include the following:

- Plants exhibit interesting behaviors; does this entail that they are conscious to some extent?

- What are the requirements for a living organism to be conscious? Do plants meet these requirements?

- What does the possibility of plant sentience/consciousness entail for the study of the evolution of consciousness?

- Is it just a categorical mistake to attribute consciousness to plants?

- Can we talk about different levels or degrees of consciousness?

\section{How to submit?}

Deadline: June 1 $\mathbf{1}^{\text {st }}, \mathbf{2 0 2 0}$

Please submit your papers (max. 9000 words including footnotes, references, abstract, etc.) to vgalian@uwo.ca with subject "Paper Special Issue JCS".

For more information, including bibliography and more detailed descriptions of the topics and questions to be addressed in the papers submitted to the special issue, please contact the guest editors at vgalian@uwo.ca (Vicente) or mso693@uowmail.edu.au (Miguel). 